\title{
Tiempos de fútbol
}

\author{
Julio HEVIA GARRIDO LECCA
}

\section{PARA ENTRAR EN CALOR, UN PARALELO}

Recordemos con Vicente Verdú que la creación del básquet norteamericano obedeció a un pedido muy puntual. Dicha solicitud especificaba la necesidad de crear un juego harto peculiar. Así pues, tal divertimento debía reflejar, de la manera más palpable, el modo de vida auspiciado y venerado en esa nación: competitividad permanente, trajín en todos los rincones, luchas fragorosas, cuerpos elevándose y, sobre todo, conquista de las alturas.

En contraposición a dicho perfil, el fútbol suele implicar, para la mayoría de casos y funciones, una reivindicación ostensible de las piernas. Su uso leal o violento, sutil o prosaico, desprende admiraciones y censuras. Cualquiera fuera el caso, en el llamado soccer, la aparición de las extremidades superiores estará siempre remitiéndonos a un borde. Clausura del avance anterior y devolución del balón a la circulación, en el caso de las intervenciones del arquero; suspensión de las acciones, sanción de un penal e incluso expulsión por cometer hand; tregua y reinicio del juego, cuando de la ejecución de un lateral se trata.

Sea como fuere, en medio de lluvias portentosas o calores insufribles, no es dificil detectar la fascinación que el fútbol suscita en el ciudadano medio; por no hablar de la multiplicación de su alcance, a propósito de las bondades tecnológicas implementadas para su espectacularización. Umberto Eco ha comentado, por ejemplo, que a diferencia del rigor y especificidad que otras temáticas exigen, las opiniones es- 
grimidas a propósito del balompié son permeables a las impresiones más inmediatas. He ahí los cambios súbitos que conectan la euforia con el desánimo; he ahí la diversidad de itinerarios asociativos que la conversa incluye. Hermandad infantil, diría Verdú, ésa que nos devuelve al tiempo de los recuerdos elementales. Períodos remotos en los que la práctica del juego se adhería indisoluble a un relato siempre presto a ser corregido y editado. Prehistoria de la que sólo queda indemne la pelota, el balón, el esférico.

Y mientras el balón corre, mientras se esconde y aquieta o es violentamente despedido, uno se informa de los caracteres que entran en juego, de los atributos que la lucha reclama y desempolva. Pensemos, por ejemplo, en la dramaturgia lúdica que el mundial de Francia ha significado. Desplegándose en toda su dimensión, Holanda activó ante Brasil una conciencia afin con el espectáculo, aunque poco interesada en concretar la cantidad de oportunidades que hubo de fabricar. En la otra orilla, una porfia contra la adversidad y sus abrumadores pesos, como la de México contra Alemania y Holanda. Incluso el afán por oponer la magia individual a la eficacia del conjunto, como fue el caso de Brasil ante Francia. Quizás el sueño de ganar una sola partida y con ella consumar un reajuste en otro terreno: Irán frente a Estados Unidos o Argentina ante Inglaterra. Por no hablar del planteamiento hermético, enclaustrado, casi policiaco de Italia lanzando el veneno de sus esporádicos dardos.

$Y$ es que en el fútbol todo es histórico, mientras que en el básquet, si retomamos el paralelo, suele homenajearse lo efimero. En el fútbol cada gol tiene valor en sí mismo, acusa un peso ontológico, de allí que a menor cantidad de goles, más paridad. Paradójicamente, en el básquet el equilibrio de fuerzas tendrá que ver con un sinnúmero de canastas convertidas. La geometría del fútbol nos remite a un saber guerrero, a una exploración terrenal, a luchas pretéritas; la arquitectura del básquet es del orden vertical, ligándose, en su levedad, a las pugnas contra la gravitación y a las conquistas astronómicas. El espectador de fútbol demanda una epopeya; el espectador de básquet se ha habituado a las variaciones de un juego bursátil.

\section{MIRAR Y ADMIRAR}

Y a propósito de historias, Rinus Michels, entrenador holandés, confesaba que la impecable estilística de su siempre recordada "naranja mecánica", no tuvo más inspiración 
que el Brasil de México 70. Cómo no evocar aquella vanguardia auriverde, en la que Pelé, Rivelino, Tostao, Jairzinho y, eventualmente, Paulo César desarrollaban un trabajo ofensivo demoledor. De ese gran equipo, Michels rescataba la capacidad de sus hombres para imprimir marcas asfixiantes cuando perdian el control del balón. Seguramente pocos pudieron rescatar tal pressing, ese lado laborioso, ciertamente poco espectacular, del entonces tricampeón mundial.

Otra mirada, sin duda, la de Michels. Mirada que implicaba, por cierto, un tiempo por venir, un planteamiento diferente. La eclosión de la "naranja mecánica" supuso, más tarde, dos subcampeonatos mundiales, conseguidos ante los dueños de casa: Alemania y Argentina. Hay, pues, "n" modos de considerar el fútbol, porque para cada país y cada equipo, los recursos con que se cuenta y el color con que la realidad es mirada, desprenden tratamientos y aspiraciones diversas. Muchos puntos de vista, literalmente entendidos, que el fútbol concita. Seguramente en nombre de esa diversidad un periodista peruano, no aplastado por las ilusiones del consenso, dijo que "en Latinoamérica el fútbol es una revancha, mientras que en Europa sólo es un juego, por más serio que fuese".

Sabemos de la euforia compartida entre el locutor radial y su escucha. De las diferentes visiones, matices y handicaps que el asistente al estadio canjea con el telespectador. De la incidencia que alcanzan, en la contemplación del juego, la retrospección ilusa de los logros pretéritos y la prospección desmesurada que confunde golondrinas con veranos. Yendo incluso al terreno más llano de las graderías: ¿es análogo instalarse en la zona baja (contra el alambrado, por ejemplo) que en las alturas de las tribunas y los palcos? ¿Existe para la apreciación óptica y la degustación estética, una zona que no se diluya en las incidencias de la superficie, un atalaya que deje de perderse en el boceto abstracto de las distancias?

Una cosa es cierta: el que más cerca está, más permeable resulta a los acontecimientos. Quien a mayor distancia se instala, mayor esfuerzo efectuará para establecer la deseada conexión. La cancha deviene alfombra o trapecio, según la perspectiva; rombo o tablero, en función de la ubicación. Y sin embargo, en medio del itinerario visual, ruidos y voces envuelven la atmósfera; cánticos y arengas invaden el audio; apelativos y agresiones tornan cada vez más frágiles las intervenciones aisladas. Todo se entreteje, todo se trenza, nada es independiente.

Lo fundamental para la masa enclaustrada, para la masa detenida y contenida, no es el alcance de una voz, ni la 
fuerza de cada grito; menos aún, el ímpetu de las expresiones aisladas sino la fuga concertada de todos los segmentos que, como los miembros de una manada, huyen al unísono. Articulación que reposa en la simultaneidad; trabajo sincrónico que va a evidenciar el funcionamiento de una máquina abstracta. Vemos que la configuración de efectos diversos, de recursos heterogéneos, de códigos entrecruzados, torna inútil el propósito de detectar causas primigenias. Y es que las masas llevan una existencia rítmica que para mejor unificarse, precisan de dividir a cada cuerpo en "n" órganos. Cabezas alineadas, cuerpos apiñados, rostros teñidos, juegos corales, olas, flujos, ondas. Cualquier sacrificio cabe en nombre de la descarga, del gol, instante supremo que todo lo nivela.

\section{NO LLORES POR Mí, ARGENTINA}

Volvamos a la cancha. Nuestros afamados vecinos, los argentinos, se preguntaron al cabo de su caída en cuartos de final: ¿A qué jugó Argentina? ¿Por qué le regaló el campo y la pelota tan abiertamente a un rival del poderío de Holanda? ¿Por qué el triunfo ante Inglaterra tuvo caracteres tan dramáticos? Un equipo, lo dijeron ellos, demasiado preparado para reaccionar, mas no para tomar iniciativas. Se habló de una italianización del fútbol argentino que, sin lugar a dudas, no arranca con el comando de Passarella. En el fútbol argentino, el amor a la planificación se ha venido ligando a un indiscutible énfasis en la precaución. Esos rigores consiguieron solaparse, de muy buen grado, mientras duró la brillante meseta que Maradona y colaboradores obsequiaron al espectador mundial. Del buen toque argentino han sobrevivido, entretanto, mínimas dosis y nadie dudaría que el propio Bilardo hizo lo suyo, dentro y fuera del campo, para que el nervio lo pusieran todos y las ideas sólo unos cuantos.

Hagamos memoria: ¿No fue acaso el propio Estudiantes de la Plata que ante el AC Milan de Italia llevó hasta el extremo la preocupación perversa por los resultados apretados y las marcas fascistas? ¿No fue alli, en aquella final intercontinental, donde el arquero Poletti debió ser suspendido por un maltrato sin precedentes a un delantero rival? Recientemente Menotti lo sentenciaba mejor que nadie: "Argentina puede ganar, puede perder o puede empatar... pero Argentina no puede jugar bien... Argentina hace mucho que no juega bien". En buena cuenta, Menotti critica esa servidumbre utilitarista que obliga al fútbol a cobijarse bajo unos fines que justifican todos los medios. No estará demás recordar que 
justamente Passarella fue el capitán de la selección que Menotti condujo en el mundial del 78. En aquel año, contra el viento de los pronósticos y la marea de las probabilidades, Argentina, selección anfitriona, se impuso categóricamente sobre Holanda en la final. Infatigablemente apoyado por el fervor del duodécimo jugador, aquel equipo supo hacer del deseo y la necesidad una sola causa, empresa para la que contó con figuras de gran jerarquía en todas sus líneas. Entre otros, Fillol, Ardiles y Kempes. Sin embargo, de allí para adelante, poco es lo que ha quedado en común entre Menotti y Passarella. Poco es lo que ha quedado en común entre sus modos de ver y de querer el fútbol.

\section{¿DE QUÉ LÓGICA(S) HABLAMOS?}

Para afirmar alegremente que "en el fútbol no hay lógica", habría que omitir la diversidad de planos que se entrecruzan en la performance de los equipos y el rendimiento de sus jugadores. Un inventario aleatorio revelaría el admirable trabajo que hay en los denominados pases al vacio y en el ejercicio de la trampa del offside; la sucesión nada azarosa de las entregas y devoluciones o de lo que hoy se llama "asistencias" al gol. No en vano suele celebrarse la milimétrica administración del instante en las triangulaciones y en las trepadas de los carrileros. Inversamente, se detecta en los equipos faltas de sincronización; episodios en los que se transita entre uno y otro error; entre defensas que dejan de intervenir pensando en la intervención del otro o cuando los arqueros calculan mal la distancia que hay entre su posición y la de su valla. En vez de una lógica de la permanencia, en el fútbol y en la vida se suele constatar una lógica de la intermitencia. $\mathrm{O}$, para decirlo con Virilio, una estética de la desaparición.

Lejos entonces de una cultura psicológica que insiste en reclamar problemas puramente individuales y adjudicar responsabilidades personales, el fútbol grafica otra dinámica. A saber, lo que ocurre entre uno y otro equipo; lo que sucede entre uno y otro jugador; los aciertos y errores entre los volantes y su defensa o entre aquéllos y sus delanteros. Aunque sea triste recordarlo, los goles que un célebre matador mapochino le convirtiera al Perú en la última eliminatoria, no se debieron exclusiva y prioritariamente a la veteranía del golero o a la técnica lentitud de su líbero, sino básicamente a lo que pasó entre ellos, a lo que no debió pasar entre ellos. Por ese "entre" pasó, como sabemos, todo el mundo. En consecuencia, una cosa es no poder prever lo que va a ocurrir en 
el campo o estar incapacitado de ejercer la futurología con respecto a los resultados; otra, muy diferente, es señalar mecánica e ingenuamente que "en el fútbol no hay lógica". La ignorancia es atrevida, ya lo sabemos, pero hay vicios mentales cuya maternidad sólo puede ser reclamada por la inercia del espíritu y la comodidad del lugar común.

Para decirlo de otro modo, en el fútbol no hay una lógica sino un conjunto de ellas, las mismas que deben ser rescatadas sea cual fuere el tipo de intereses que animan al analista, al observador o al participante del juego. Ya nos lo había advertido von Neuman, el inventor de la teoría de los juegos y uno de los principales propulsores del uso de las probabilidades en la economía de mercado: alli donde hay contrincantes y reglas, hay también tácticas para imponerse sobre el otro. Esas tácticas, agregaba von Neuman, son siempre racionales y ello supone su permanente reajuste, su flexibilidad en función de la respuesta ajena ¿Será que sólo somos capaces de rescatar lógicas y racionalidades en caso de triunfos indiscutibles y para finalidades irreversibles? Un psicologismo barato, sospechosamente extendido, tenderá a hablar, como en el caso de Ronaldo, de regresiones a lo emotivo o de caídas en el foso insondable de los instintos. Reclamamos teorias donde no las hay, esencias donde reinan las apariencias, decía Wittgenstein.

Insistamos con los tiempos. Durante un partido, uno, dos o más jugadores transitan de la posición correcta a la incorrecta. Ello no siempre obedece a la torpeza de los infractores sino a la destreza y perfección con que sus contrincantes sepan instalarlos fuera del juego. Técnicamente inhabilitados, aquéllos son objeto de una extemporanización. Y ya que de temporalidades se trata, es preciso enfatizar que la posición adelantada en el espacio futbolístico supone un auténtico e incontestable retraso en el tiempo del juego. El adelantamiento espacial va a coincidir con el desfase temporal. Se cae entonces en un espacio ilícito, pero se cae por una pérdida de tiempo. Si el ser es en el tiempo, como Heidegger indicaba, aquí se concreta un auténtico desalojo de ese ser. Percibimos cómo el tiempo abandona al ser; como éste, en buena cuenta, deja de ser.

Debemos comentar, eso sí, que la trampa del offside, recurso altamente planificado y siempre riesgoso, encontró su expansión inicial en Europa y sus posteriores reflejos en América. Fue sobre todo en el fútbol italiano donde el fuerade-juego se constituyó en una invalorable arma de adormecimiento y paralización del rival. Pertinente es recordar que en medio de ese estilo, consuetudinariamente especulador, 
los italianos crearon también el denominado cerrojo y, con él, a los primeros líberos de la historia. Por estos lares, en cambio, tales tácticas se diseminaron en función de la premura o tardanza con que los estilos tercermundistas tendieran a reproducir las disciplinas de punta.

\section{PENA(LE)S Y GLORIAS}

Vayamos a un asunto polémico: la definición por penales. Divergencias al margen, la puesta en marcha de tales duelos, suerte de sintesis del fútbol o de su pura y simple distorsión, ha generado glorias y desdichas por doquier. Basta evocar los dramas de Zico y de Platini, los de Stielike y Baggio y la algarabía de sus encumbrados oponentes. De Goycochea, arquero argentino, se dijo que no pasaba de ser un eficaz atajador bajo los tres palos. Nada casual resultó que esa misma especialidad, aunada al conservadurismo albiceleste de los noventa, lo colocase al borde de la gloria. Así pues, a fuerza de atajar penales, Goycochea llevó a su equipo hasta la mismísima final con Alemania.

Recientemente, el mismo golero declaraba que para adivinar la dirección del balón, había que reconocer a los diestros y a los zurdos, además de recoger las miradas que los ejecutantes efectúan sobre algunas zonas del arco. En el extremo debe captarse un dato, cuyo imperceptible asomo suele anticipar los propios desenlaces: cierta inclinación del pie de apoyo que, en el momento de la ejecución, presenta el rival. Sobre esos índices, confesaba Goycochea, decidir la dirección y altura de sus reacciones. Nada entonces de magia o de iluminación, nada que se agote en la pura intuición o en el mero hechizo, sino un juego progresivamente acelerado de reconocimientos y simulaciones que apremian, hasta el último segundo, a los protagonistas.

Para llegar a esos umbrales hay que anexar otros saberes; hay otros aprendizajes que tomar en cuenta; hay otras disciplinas a las que el cuerpo debió acomodarse. Nos referimos a una serie de acciones y reacciones que fueron objeto de un adiestramiento sistemático; hábitos que fueron consolidados a puerta cerrada; ensayos prefabricados en esa dimensión que llamamos "de laboratorio". Curiosamente J.F. Sanfillipo, legendario goleador argentino y posterior comentarista en su país, le reclamaba al mismo Goycochea no haber estudiado suficientemente a la ofensiva colombiana, cuyos integrantes lo atiborraron de goles en el partido de vuelta jugado en Argentina durante las eliminatorias del mundial 
Estados Unidos 94. Con un sonoro y humillante 5-0, tal encuentro fue espectacularmente resuelto por los colombianos y, en opinión de Sanfillipo, el golero albiceleste fue cómplice de algunas de las conquistas que le fueron encajadas. La amargura del veterano ex jugador se veía refrendada en la idea de que los delanteros y los arqueros están profesionalmente obligados a estudiarse mutuamente, máxime si se han enfrentado en otras ocasiones.

Se infiere de la cuestión aquí comentada el protagonismo adquirido por los arqueros en el fútbol moderno. Obviamente, los botones privilegiados de esa muestra resultan, en Latinoamérica, Higuita primero y Chilavert después. Arqueros atacantes, arqueros dribleadores, y lo que es más sintomático: arqueros ejecutantes. Síntomas de una reversión de todas las funciones en la cancha. El arquero que humilla al otro arquero, el golero que ejecuta mejor que nadie los tiros libres y que sabe como minimizar las probabilidades de error en el disparo de los doce pasos. Situaciones que ya no parecen excepcionales ni anecdóticas en el rectángulo de juego.

\section{TENSIÓN Y TORSIÓN}

En el fútbol hay un principio: a fuerzas iguales, serán ciertas individualidades las que marquen el desequilibrio. Sin embargo, hoy por hoy, en nombre de las precauciones que la mayoría de entrenadores toman, los llamados manoa-mano entre defensas y delanteros, o entre delanteros y arqueros, se reducen al mínimo. Es el reino de los balones divididos. De ahí que a potencias equivalentes, el fracaso de unos y el éxito de otros tendrá que ver con un leve pestañeo; ante un campo que mina la mayoria de sus trayectorias con marcas asfixiantes, y donde el llamado pressing combina seguimientos por parejas con emplazamientos zonales, se tratará de explorar los espacios más débiles, de explotar los nexos menos trabajados.

Es así que el drama más palpable del defensa contemporáneo sea enfrentarse a un mortal dos-uno con los rivales, y no tener más opción que buscar la humanidad del que lleva el esférico. Valdano ha señalado, por ejemplo, que donde vaya Ronaldo -léase Barcelona de España, Inter de Italia, Brasil 98- sufre un problema análogo: solo contra el mundo, responsable exclusivo y solitario de las empresas que su equipo y su pueblo depositan sobre él. Todo Brasil, bueno es señalarlo, confiaba en la ventaja y soltura que la compañía de Romario debía otorgarle, pero otra dupla, la de Zagalo-Zico se 
opuso a ello pretextando ciertas razones o razonando a partir de ciertos pretextos.

José Carlos Amaral, estratega brasileño radicado en el Perú, declaraba, antes de la derrota con Noruega en el pasado mundial de Francia, que aparentemente Brasil no había conseguido sacudirse del efecto nefasto que le significó caer ante Italia, en España 82. Según se recuerda, la selección de Zico, Sócrates, Falcao, Junior y Eder, declinó ante una Italia que llevó al colmo de su eficacia unos planteamientos ardorosamente defendidos. Lo curioso es que en aquel match, Brasil anduvo al frente en el marcador en dos ocasiones y otras tantas veces fue empatado por la squadra azurra. Los entonces tricampeones mundiales sólo supieron aferrarse al libreto, hoy abandonado, de atacante inefable, de dominador romántico, de cuadro ajeno a los plazos cronológicos. Italia supo divisar y explotar la debilidad del poderoso. A Brasil la lección pareció no bastarle pues, años más tarde, entre la astucia del "Pájaro" Caniggia y la iluminación de Maradona redujeron mais uma vez al Goliat auriverde.

A partir de esas fechas Brasil tiende, por lo general, a aquietar el juego y el balón cuando establece la mínima diferencia, cuando consigue anticiparse en el marcador. Amaral habló de lo que el resto prefirió ocultar: la veteranía de Dunga, la falta de recursos de Baiano, la timidez de Rivaldo, las demoras de Leonardo y la pobreza de variantes ofensivas en el seleccionado brasileño. Es evidente que los triunfos contra Chile, Dinamarca y Holanda aplacaron temporalmente las preocupaciones y postergaron la validez de tal diagnóstico. Sin embargo, dichas apreciaciones quedaron absoluta y patéticamente confirmadas en el 0-3 sufrido por Brasil ante la danza tricolor de Zidane \& compañía. ¿Quién dijo que en el fútbol no hay lógica? La insatisfacción con el rendimiento de la selección brasileña se remonta, no obstante, al mundial de Estados Unidos 94, cuando los auriverdes accedieron al tetracampeonato vía penales, demostración que los entendidos consideraron poco digna e innecesariamente austera.

En el Perú y en el mundo se han multiplicado las reacciones contra el 3-0 que permitió a Francia incluirse en la elite de campeones mundiales de fútbol. Entre quejas y sospechas las fábulas encuentran su abono: la epilepsia de Ronaldo y la taquicardia de Zagalo, el inexplicable cansancio y el aún más inexplicable desinterés. Los problemas internos y las presiones externas. Argumentos que revelan en su mismo fundamento la incapacidad para aceptar la distancia que el trabajo levanta. La técnica, como nos recuerda Lyotard, no es una invención del hombre; es el hombre quien resulta inven- 
ción de la técnica. Por último, si algo hay que decir en descargo de Zagalo es lo que éste arguyó antes del mundial: no he tenido suficiente tiempo a los jugadores. Del tiempo depende, como se ve, todo lo que el fútbol es capaz de ofrecer y sustraer.

\section{MEMORIA DE FANTASMAS}

Otras cronologias, mediatas, a largo plazo se imponen en el fútbol. Se trata de un registro acumulativo, transmitido de generación en generación. Trabajo imaginario cuyos efectos se reiteran ante los mismos rivales, cuyas sombras se extienden a despecho del transcurso histórico. He ahí la memoria larga, la de los respetos y los miedos; la de los prestigios y los lastres; la de los colonizadores y los colonizados.

Ataquemos el asunto desde otra perspectiva, ésa que se liga a las grandes y a las pequeñas historias; ésa que opone a recuerdos obsesos y fechas traumáticas, olvidos saludables y evacuaciones precisas. Y es que pre-ocuparse y pre-juiciar son, literalmente, modos de ocuparse y enjuiciar antes... de tiempo. Con certeza, ése no fue el tenor con que Nigeria, México y sobre todo Croacia encararon el mundial en Francia. Recientemente conquistada la historia en el caso de Croacia; demasiado reciente e incluso auspiciosamente exitosa entre los nigerianos; sin figuración importante para los mexicanos, esas tres selecciones constituyeron modelos ejemplares de celebración de un juego librado en el presente. Inapelables modos de luchar palmo a palmo contra rivales que la cátedra sindicaba como triunfadores. Fue así que estos últimos debieron aceptar, contra su deseo, que la pretendida superioridad y el favoritismo imaginario no alcanzaban para ocultar las inoperancias y las limitaciones más concretas.

Que la anticipación táctica sea bienvenida y celebrada en el campo de juego no debe hacernos concluir que otras anticipaciones, aquéllas de los pronósticos y las expectativas, se vean siempre confirmadas. España, en el reciente mundial francés, fue la principal víctima de una rimbombante campaña publicitaria que Nigeria convirtió en triste flagelo. Así mismo Colombia debió inclinarse dos veces, en un lapso de ocho años, ante un fútbol rumano que no alcanzaron ni en avión. He ahí los problemas, comenta Menotti, de avizorar panoramas halagüeños donde no hay una tradición mundialista que los soporte. Constituye una excepción que equipos $\sin$ mayor trayectoria consigan liberarse de la inexperiencia, de la falta de roce, de la ausencia de referentes 
para confrontar, con dignidad, un torneo como el de Francia. Por ello tales excepciones suelen ser saludadas con paternal beneplácito, mientras la cátedra certifica entre africanos, orientales y centroamericanos, un espíritu a prueba de balas; una existencia impermeable a los pronósticos. Los equipos "chicos" tendrían a favor la recuperación del juego, en su acepción más libre e infantil. Probable reflejo del minimo espacio que los rivales le conceden, no ha de sorprender que ellos mismos se tomen la competencia con cierta ligereza, y que incluso suelan ignorar lo que es jugar contra el reloj o enfriar un partido Ese desenfado diluye las presiones formales, y en los casos más afortunados suele desdibujar, sin proponérselo, los pergaminos que adornaban al rival.

Lo típico, lo más probable, es que los equipos de nivel medio redondeen performances más o menos dignas, a costa de mucho tesón y esfuerzo: plus que habrán de pagar en los tramos siguientes. Entretanto, los grandes candidatos suelen ir de menos a más, calculando y dosificando, procurando que la propia capacidad se adhiera a los fantasmas del aspirante de turno. El dueño de casa se juega un campeonato aparte, pues si bien la dificultad de los rivales es grande, sobre todo si son equipos de relieve, la empresa que le resta al local no es desdeñable. De allí que Francia, en su mundial, haya sido de los campeones locales más convincentes que recuerde la historia. No sólo porque contó con figuras cuyo brillo sería ocioso ignorar, ganó todos sus partidos y exhibió una defensa casi inexpugnable. No sólo por ser fiel a un estilo mantenido a pesar de cambios y relevos, sino porque a pesar de carecer de delanteros de punta eficaces, supo revertir los planteamientos siempre defensivos con que la mayoria de sus rivales salieron a jugarle.

Mal que nos pese, en el fútbol como en la obra de Rulfo, el tiempo de los vivos se funde con el de los muertos; los cadáveres sobreviven a sus deudos. Los relojes de una realidad siempre cronometrada parecen derretirse, como en algún fresco de Dalí, ante otros fantasmas. Aquello que con tanta vitalidad se desprende de la obra de Nietzsche, vale decir, la exigencia de superar los tiempos idos y revertir las huellas pretéritas, de liberar las ataduras que nos sujetan a los tiempos edípicos, resulta harto costoso. El fútbol nos da muestras permanentes del modo y frecuencia con que las marcas de antaño van a impedir que los nuevos candidatos consigan ver que el pasado puede también tasarse desde el presente. En vez de ello, es típico que dichos aspirantes se vean abrumados por los pergaminos del rival y sigan creyendo que el presente hay que verlo desde el pasado. Para plantearlo en 
los términos del mismo filósofo alemán, se diría que en la final y ante el peso de la historia de Brasil, Francia levantó su propia genealogía, traicionó todas las jerarquías, obligó al consuetudinario doblegador a doblegarse.

Debe recordarse que México estuvo a punto de vencer a Alemania, pero no lo logró; que Holanda pudo y debió concretarlo ante Brasil, pero no lo hizo; que Inglaterra, contra viento y marea, estuvo a milimetros de lograrlo ante Argentina. Pero que Nigeria sí lo concretó ante España y fundamentalmente Croacia ante Alemania. Que librarse de los fantasmas cuesta mucho, a nadie le cabe la menor duda, pero que sea imposible hacerlo: eso ya suena a cine terror. Y a propósito del terror, recordemos que el fútbol peruano, todavia desfasado para los mundiales, aunque a veces insinuante a nivel de clubes, redondeó algunos de sus más publicitados triunfos cuando sobre sus espaldas no recaía expectativa alguna. Inversamente las grandes debacles en las que debió sumirse se han ligado a la imposibilidad de conservar lo conquistado; a la inconsistencia para defender el sitial al que se hubo accedido, de responder a la exigencia despertada entre los interesados. Lo cierto es que alli estamos, entre ascensos furtivos y descensos traumáticos.

\section{CUERPOS DÓCILES}

Que todo jugador suele ser la sede de una serie de deseos, en ocasiones irreductibles, parece indudable; que en él se intersecten las fantasias del hincha con las exigencias del cuerpo técnico no es cosa nueva. Lo novedoso, en última instancia, son las astronómicas cifras que se movilizan en el mercado futbolístico. Es precisamente bajo tales intereses y a propósito de los montos allí depositados que podemos concluir un par de cosas sobre el caso Ronaldo. Que no es una máquina infalible, aunque muchas veces pueda parecerlo. Que también puede perder el sueño, por todo lo que en él se cifra; por todo lo que habrá de perder, si no acierta; por todo lo que podrá multiplicar, si sigue rindiendo.

Tal vez hayamos olvidado el caso, tristemente célebre, de aquel defensor colombiano, Andrés Escobar, ultimado en su propia tierra al retorno de Estados Unidos. O tal vez la fuerza de la costumbre impide nos sorprendamos del gran jaleo que en torno a la figura de Maradona y sus tragedias arma la prensa argentina para todo el orbe. Delirios al margen, Escobar y Maradona, cada cual a su modo, serian las víctimas de un juego que otrora sirviera para sublimar los intereses béli- 
cos y que, hoy por hoy, resulta capaz de destilar los pretextos necesarios para el desencadenamiento de otras tantas guerras de intereses.

Alli se enfilan y afilan los oscuros revanchismos nacionalistas; las exigencias de todos los sponsors del planeta; el mercado de los pases y las primas; el de las tarifas de transmisión vía satélite; y el del valor de cada gol, de cada campeonato, de cada título. Es por todo ello que algunos autores han sabido ver en la plaza del fútbol actual resabios de una economía feudal, reediciones de un funcionamiento gremial como el que convocaba a los artesanos del medioevo, asignando dueño y destino a su producción, antes de que ella se materializara. En todo caso, Occidente posee una larga data con respecto al adiestramiento de las destrezas motoras y la expulsión de las taras posturales. Gestación, pues, de un ser definido por su capacidad instrumental; generación automática de un cuerpo dócil.

\section{VIENTOS A FAVOR, VIENTOS EN CONTRA}

Hay todavía otros tiempos que tocar, como cuando se dice que no sólo se juega contra el rival sino además, y por si fuera poco, contra el tiempo. En rigor se trata de lo mismo pues el tiempo que un equipo gana es el que le resta al rival, el tiempo conquistado es el que le está siendo usurpado al rival. El balón administrado o rechazado por el equipo victorioso es el balón requerido por el que soporta la desventaja. No faltan los equipos que, en su desesperación y ceguera, se han peleado con el tiempo y hay los que, con su calma y sapiencia, son sus aliados. Hay quienes recalientan y hay quienes congelan; en ese sentido, caben en la cancha, temperaturas para todos los gustos. Resulta dramáticamente interesante que en las postrimerias del encuentro se presenten oportunidades de variar el marcador y que allí, una vez más, se establezcan las diferencias entre dos frialdades (la del que define y la del que contiene) o entre dos esterilidades (la del que no puede traducir o la del que no puede evitar).

A propósito del progresivo perfeccionamiento de las tácticas defensivas, de los reflejos y golpes de vista de los guardapiolas, y de la alta expectativa que se cifra sobre los goles conseguidos, es frecuente que el equipo que más oportunidades fabrique en partidos de alta competitividad no sea precisamente quien consiga romper el cerco que el arco rival simboliza. Suerte de correlación inversa, pues ahí no se certifica la supuesta proporcionalidad guardada entre la permanente 
invasión del campo rival y su traducción en goles. La paradoja se diluye cuando al constatar las ventajas de un juego especulador que regala la cancha mientras abona las condiciones para el contraataque letal. Así, cuando un equipo apertrechado consigue en una escapada feliz vencer la resistencia del contrincante, el beneplácito y la desazón se duplican, pues la trampa que tiende el vencedor ha supuesto una inversión menos generosa; mientras que el providencial perdedor añade a la herida de la conquista ajena la esterilidad de sus esfuerzos. Hace unos meses hemos visto clasificar de visitante, bajo ese peculiar modo, a Vasco da Gama. En consecuencia el poderoso River Plate, en el mismísimo Monumental de Buenos Aires, se despidió de la Copa Libertadores. Entretanto los comentaristas destacaban, claro está, la "falta de lógica".

Paraguay e Italia lo intentaron ante Francia; Argentina y Yugoslavia lo pretendieron ante Holanda. No estuvieron lejos, pero no bastó. En El Gráfico se llegó a comentar que con respecto a Holanda, Argentina tenía poco fútbol y mucho gol: el empate del "Piojo" López y el remate al parante de Batistuta no son poca cosa para un equipo que llegó escasamente a la otra cancha. En contraposición, podría afirmarse que Holanda, fiel a su toque, a su rotación, a la generación permanente de opciones fue, en general, un once con poco gol, en relación con todo el fútbol que regaló. Paraguay llevó su esfuerzo a limites cuasi gloriosos ante Francia, pero Blanc lo dejó todo en blanco. Entretanto Italia apostó por Vieri, pero sus recursos no siempre se vieron.

Otro modo de jugar con el tiempo en contra supone resistir los últimos aires de un adversario que se lanza, ya no en busca del triunfo consagratorio, sino de un empate que nivele los méritos y homologue las cuentas. Vimos así a Chile tres veces consecutivas a punto de arrancar sendos triunfos, y tres veces consecutivas siendo empatado sobre las postrimerías o en los descuentos. Más allá de las ganas del equipo araucano, se pudo certificar la ausencia de calma en el medio, de jerarquía atrás, de experiencia en una y otra línea. Recuérdese que en los pasajes aludidos el equipo vecino fue bombardeado en su zona aérea, siendo tales maniobras índices inequívocos de la escasez ideativa o del ciego atolondramiento de sus rivales. Por ende, una dosis de frialdad y talento con el balón hubiera resultado vital. Lamentablemente, los chilenos no contaron con esos recursos y, en medio del orgu1lo, un cierto sabor a injusticia agrió sus paladares. Siempre se puede concluir que cada cual juega hasta donde el rival lo permite. Lo fundamental, en todo caso, no es la capacidad 
aislada de cada cual, sino lo que en el juego se contrapone y entreteje. Suele suceder que la exagerada conciencia de estar jugando contra rivales de mucha jerarquía impide considerar con qué compañeros se cuenta. Un excesivo respeto al rival suele caminar al lado de una desaparición del compañero.

\section{EXPECTA-ACTIVAS Y ESPECTA-ACTORES}

La masa ama la densidad, indica Canetti. Tal propiedad se afirma en la multiplicación de sus elementos; en la nivelación de sus componentes. La accesibilidad visual por la que todos luchan, pagan y se aglomeran va a focalizarse en el campo de juego. El resto es accesorio, marginal, entrópico: otro espectáculo. No son, sin embargo, los individuos los que territorializan las graderias; se trata de la gente, del pueblo, de las barras. Reunirse, congregarse será acá equivalente a formar anillos, a conectar circuitos, a trazar circunferencias. Dándole la espalda a la ciudad, al trabajo, a la supuesta realidad se divisan las tribus que hoy, más que nunca, se adornan el rostro y el cuerpo o que, en su defecto, hacen del cuerpo todo su auténtico rostro. Así pues, por lo que disemina y contagia, por lo que informa y deforma, por lo que contiene y libera, el fútbol sigue siendo escenario idóneo para que los acosos y las persecuciones se resuelvan lúdicamente.

Por añadidura, los silencios acusan fisuras. La pasividad del mero asistente ha sido desterrada, desterritorializada. Asistimos a las exequias del espectador neutro, del observador intelectualizado; al exorcismo de un ente equilibrado; a la muerte del superyo. Hasta el mismo televidente abandona su aislamiento y va en busca de la compañia requerida para seguir las incidencias del fútbol. A la fuerza de un "dónde" pretérito, se suma la urgencia de un "con quién" actual.

De ese modo, el devenir-hooligan, alerta, belicoso, iracundo, ya no se explica a partir de la desocupación laboral o de la marginalidad adolescente. Recientes informes revelan que las cabezas visibles de esas lineas duras son ciudadanos normales y corrientes, dueños de posiciones holgadas e incluso respetados en sus comunidades de origen. Una cosa es cierta: toda esa parafernalia de las barras bravas no podría ser reconocida sin el soporte de unos medios masivos que contribuyeron a la afirmación de esos impactos y, esos territorios. Un modo relativamente fácil de tornarse célebre, el de estas tribus de fin de siglo. Fascistamente célebre se diría. Para desconcierto de muchos, Bobby Charlton, otrora gran 
jugador y actual dirigente del fútbol británico, afirmó últimamente que los mayores escándalos perpetrados por los hooligans se han llevado a cabo fuera de Inglaterra. Tal vez en esa inclinación al desborde, en esa voluntad invasora, en esa experimentación con los límites, pueda certificarse que el hombre es, por encima de valores y principios, y como recuerda Deleuze, un animal desterritorializado.

Para terminar. Se ha afirmado que el fútbol es el retrato del pueblo, que constituye su propia huella digital. En consecuencia, sólo queda esperar que la manía massmediática por entre-vistar todo lo que alli ocurre, por entro-meterse en tal culto no altere en demasía esas marcas identitarias; que la información no engrose, más allá de lo deseable, una violencia cuyo perpetuo desborde tiene mucho que ver, lo tememos, con esos franco-miradores que las cámaras televisivas representan. Sabemos que la percepción de los rostros fascinados y superpuestos tiene, en las tribunas, algo de cu-riosamente homogéneo. Presencias otrora atisbadas en vivo por los espectadores de antaño, aficionados pacíficos o barristas bajo régimen. En términos de Baudrillard, se trata de una onda porno-gráfica. Exponiendo e imponiendo imágenes, las cámaras tornan cualquier cosa familiar o habitual, soportable o aburrida. Con ellas todo podrá ser sorprendido; pero desde ellas, nada resultará del todo sorprendente. Tampoco los desenfrenos, las catástrofes y las violaciones. Es la versión tecno de la ley del talión: Ojo por ojo, lente por lente. 